\title{
Descriptions of larval and pupal morphologies of Macrohyliota militaris (Erichson) (Silvanidae: Brontinae: Brontini)
}

\author{
Zhenhua Liu ${ }^{1,2,3}$; Adam Ślipiński ${ }^{2,4}$ \& Hong Pang ${ }^{1,5}$ \\ 1 Sun Yat-sen University (SYSU), School of Life Sciences, State Key Laboratory of Biocontrol. Guangzhou 510275, China. \\ ${ }^{2}$ Commonwealth Scientific and Industrial Research Organisation (CSIRO), Australian National Insect Collection (ANIC). \\ Canberra, Australia. \\ ${ }^{3}$ ORCID: http://orcid.org/0000-0002-2739-3305. E-mail: liuzhh22@mail2.sysu.edu.cn \\ ${ }^{4}$ ORCID: http://orcid.org/0000-0002-1216-8068. E-mail: Adam.Slipinski@csiro.au \\ ${ }^{5}$ ORCID: http://orcid.org/0000-0002-0585-3577. E-mail: Isshpang@mail.sysu.edu.cn
}

\begin{abstract}
The mature larva and pupa of the Australian silvanid species, Macrohyliota militaris (Erichson) are described from laboratory reared material. This is the first description of immature stages of Silvanidae from Australia. The larva of M. militaris conforms to the general body shape and apparent morphological features of known Brontini and is very similar to the Asian M. sculptus Yoshida \& Hirowatari. Larval and pupal features of $M$. militaris are compared with other known larvae and pupae of Brontini described in the literature.
\end{abstract}

Key-Words. Larva; Pupa; Brontini; Australia; Morphology.

\section{INTRODUCTION}

Silvanidae is a family of mostly brown and dorsally flattened beetles, comprising approximately 62 genera and 500 valid species (Thomas \& Leschen, 2010; Thomas, 2011; Karner et al., 2015; Yoshida \& Hirowatari, 2018; Yoshida et al., 2017). Historically it has been classified as a subfamily within a broadly defined Cucujidae. Based on the position of the male genitalia, Thomas (1984) divided Silvanidae into Silvaninae, with the aedeagus oriented dorso-ventrally, and Brontinae (= Uleiotinae) with the aedeagus inverted. Thomas (1984) further recognised the tribe Brontini (= Uleiotini) with externally open procoxal cavities and tribe Telephanini with procoxal cavities externally closed within the subfamily Brontinae. Brontini consists of 13 genera from all the continents (Thomas, 2003, 2011), which can usually be found under bark of dead trees. Both adults and larvae of Brontini appear to be fungivorous (Thomas, 2003; Yoshida \& Hirowatari, 2016), while Protodendrophagus antipodes Thomas, from New Zealand, was found to feed on lichens (Marris et al., 2019).

The characters of the immature stages provide important information for phylogenetic studies in Coleoptera (Lawrence et al., 2011; Leschen et al., 2005). However, informative descriptions of larvae and pupae are available only for a limited number of species only. Within Brontini, the larvae of the following genera were described: Australohyliota Thomas from Chile (Cekalovic \& Quezada, 1972), Dendrophagus Schoenherr from Europe and Asia (White, 1872; Hayashi, 1980; Klausnitzer, 2001; Thomas \& Leschen, 2010; Yoshida \& Hirowatari, 2016), Dendrophagella Sharp from New Zealand (Hudson, 1934), Macrohyliota Thomas from Asia (Yoshida \& Hirowatari, 2016), Megahyliota Thomas from Asia (Yoshida \& Hirowatari, 2016), Parahyliota Thomas from India (Pal et al., 1984; Pal \& Baraik, 2012) and Uleiota Latreille from Asia and North America (Hayashi, 1980; Thomas, 1988; Klausnitzer, 2001; Yoshida \& Hirowatari, 2016). Pupae of Macrohyliota, Megahyliota and Uleiota were reported by Yoshida \& Hirowatari (2016). While some of the previously mentioned descriptions are not complete or lack details based on dissections, they provide good morphological evidence for the monophylly of the tribe Brontini (Thomas, 1988).

During daily collecting in 2017, we collected several adults and larvae of Macrohyliota militaris (Erichson) at Black Mountain in Canberra (ACT), Australia. Three of those larvae pupated after a few days, providing good opportunity for us to describe the larva and pupa of an Australian Brontini for the first time.
Pap. Avulsos Zool., 2020; v.60.special-issue: e202060(s.i.).05 http://doi.org/10.11606/1807-0205/2020.60.special-issue.05 http://www.revistas.usp.br/paz

http://www.scielo.br/paz

Edited by: Sônia A. Casari / Gabriel Biffi

Received: 2020

Accepted: 06/11/2019

Published:
ISSN On-Line: 1807-0205

ISSN Printed: 0031-1049

ISNI: 0000-0004-0384-1825 


\section{MATERIAL AND METHODS}

This study is based on the larvae and associated adults specimens of $M$. militaris collected from Black Mountain in Canberra (Australia), under bark of dead Eucalyptus tree on 15 July 2017 by the senior author. Several larvae were reared in the Petri dishes with bark pieces; three last instar larvae pupated on 23 July 2017 and one of them was preserved in ethanol. Adult beetles from remaining two pupae emerged after 7 days. All the associated specimens are deposited in Australian National Insect Collection (ANIC). The terms used in morphological descriptions follow Thomas \& Leschen (2010).

Larvae used for dissection were macerated in $10 \%$ $\mathrm{KOH}$ to clear the muscles, then dissected and examined in open glycerol slides; the head and mandibles were dyed in Chlorazol Black diluted in glycerol. Field photos were taken by the senior author using Canon 6D camera with $100 \mathrm{~mm}$ lens. Most of the habitus and morphology images were taken using a Dun Ink BK Lab Plus system http://www. duninc.com/bk-plus-lab-system.html. Source images were then aligned and stacked in Zerene Stacker. Individual head images were taken using a Leica DFC 7000 T digital camera mounted on a Leica DIAPLAN compound microscope with LAS X software. Layers were then aligned in Helicon Focus. Further edits and plates were made in Photoshop CS6 and Photoshop CC.

\section{TAXONOMY}

\section{Silvanidae Kirby, 1837 \\ Brontinae Erichson, 1845 \\ Brontini Erichson, 1845 \\ Macrohyliota militaris (Erichson, 1842)}

\section{Descriptions of Larvae and Pupae Morphologies}

\section{Larva (last instar) (Figs. 1-2)}

Length $10-11 \mathrm{~mm}$, head width about $1.6 \mathrm{~mm}$. Body distinctly flattened and slender; lateral margins nearly parallel (Figs. 1A, 1B).

Head transverse with 5 stemmata in one group on each side; frontal arms U-shaped and complete, epicranial stem very short (Fig. 1D). Dorsal surface with two moderately long setae near each antennal insertion, a pair of long lateral setae on anterior area and three pairs near posterolateral edge, otherwise surfaces covered with several pairs of shorter setae. Ventral side (Fig. 1E): gular sutures widely separated, divergent both anteriorly and posteriorly; hypostomal rods distinct and long, diverging posteriorly; ventral surface with pair of long setae below antennal insertion and several pairs of short setae. Clypeus trapezoid, fused with frons, bearing a pair of moderately long setae on anterior area and several pairs of short setae near apex. Labrum transverse with rounded apical margin, covered with short setae. Antenna (Fig. 2B) elongate, slender, about 1.1 times as long as head width; scape relatively stout, with a long seta at mid length and some shorter and very short setae; pedicel about 1.4 times as long as scape, with short, conical sensorium and several long setae near apex and one near mid length, flagellum distinctly narrower than the basal segments. Mandible (Fig. 2F) triangular with broad basal area, apex bidentate, incisor area with two teeth on left mandible and one on right mandible; prostheca membranous, triangular and long, almost transparent; mola with asperities or small tubercles transversely arranged with a posterior and an anterior penicillus; ventral process sub-triangular with pointed apex. Ventral mouthparts deeply retracted. Maxilla (Fig. 2D) with well-developed articulating area; cardo sub-triangular and transverse; stipes large with several distinct setae; mala falcate with inner edge acute, bearing 2-3 sclerotized unci and dense setae apically; palpifer distinct. Maxillary palps 3-segmented, covered with sparse setae: first palpomere stout, the second longer than first, terminal palpomere fusiform with rounded apex. Labium with submentum trapezoid, fused with gula at middle; mentum nearly quadrate, prementum transverse with distinct palpigers laterally; ligula broad with rounded apical margin, covered with dense short setae apically and several longer setae on surface. Labial palps (Fig. 2E) two-segmented with the first segment stout, the second palpomere nearly 1.7 times as long as the first one, apex rounded. Hypopharyngeal sclerome forming transverse bar.

Tergites of thorax simple, without distinct sclerites or tubercles; integument with very fine asperities laterally, visible under high magnification only. Prothorax sub-trapezoid, widest apically, dorsum with two pairs of setae anterolaterally and one posterolaterally; venter with pair of relatively long setae anteriorly adjacent to procoxae and several short setae. Meso- and metathorax sub-rectangular with lateral margins slightly curved, widest at about middle. Mesothorax with three pairs of distinct lateral setae; metathorax with two pairs of setae on dorsum; ventral side of each segment with pair of long setae anterolaterally and several shorter setae. Thoracic spiracle annular, located between pro- and mesothorax. Coxae separated by more than two coxal diameters (Fig. 1B). Legs (Fig. 2C) elongate; trochanter subtriangular and stout with several short setae; femur about 2.4 times as long as wide, covered with several distinct setae and some sparse and short setae; tibiotarsus slender, about 6.2 times as long as wide and 1.3 times as long as femur, covered with short setae along inner edge; pretarsal claw simple. Abdomen 10 segmented; ratio of segments lengths I-VIII as 1.0: 1.3: 1.5: 1.6: 1.6: 1.5: 1.3: 0.9 . The first segment short, trapezoid, widest posteriorly, bearing pair of long setae posterolaterally; abdominal segments II-VIII each with a pair of long lateral hairs that are exfoliate. Segments II-VII with lateral margin slightly convex, with 3 pairs of distinct lateral setae; mediotergites with pair of long setae posterolaterally and pair of short setae anteriorly; each sternite with pair of long setae posterolaterally. Segment VIII distinctly narrower and shorter than VII, lateral margins almost parallel with pair of distinct posterolateral projections, extending posteriorly and bearing a long seta. Urogomphi (Fig. 2A) long 
and U-shaped, strongly bifurcate with sharp apex, gradually diverging posteriorly, each side with two setae underneath at about middle. Terminal segment posteriorly oriented, forming sub-cylindrical pygopod, with anal opening apically. Spiracles annular with distinctly crenulate peritreme (Fig. 1C) on abdominal segments I-VIII, located on very short spiracular tubes.

Remarks: The larva in a prepupa stage (Fig. 3B) is almost identical to the last instar larva, but with the stemmata almost invisible, and the setae on the pronotum almost fused with the pronotum.

\section{Pupa: (Fig. 4)}

Length $8.3 \mathrm{~mm}$. Colour of integument changing from initial khaki to rufous in latter stages preceding eclosion; colour changes are especially apparent on head, pronotum, antennae, elytra and legs. Abdomen with terminal segments surrounded by skin cast from last instar larva.
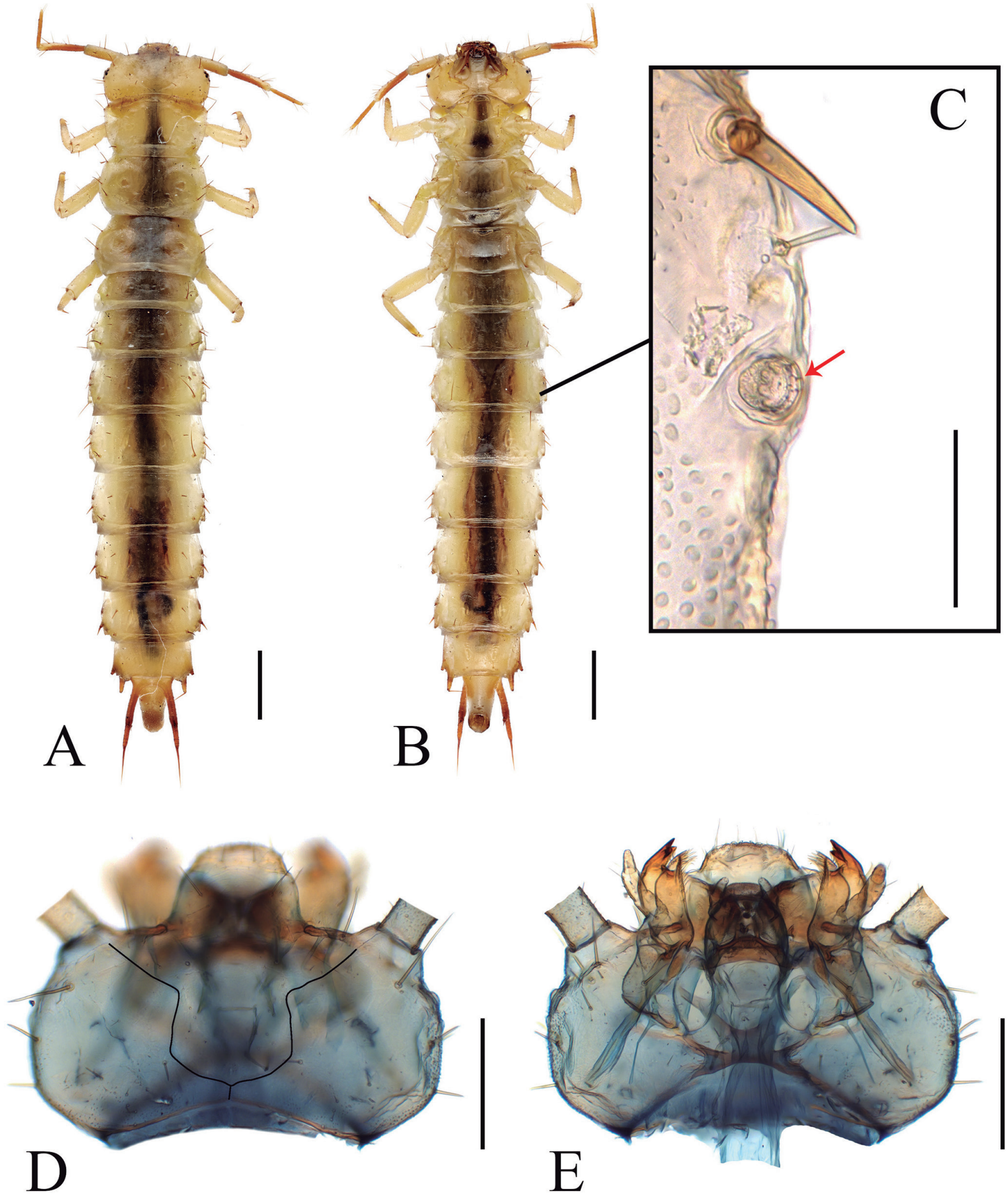

Figure 1. Larva of Macrohyliota militaris (Erichson). (A) Habitus, dorsal, (B) habitus, ventral, (C) spiracle shown in red arrow, (D) head, dorsal, frontal arms showed by black lines, (E) head, ventral. Scale bars: $1 \mathrm{~mm}$ in $A$ and $B, 0.1 \mathrm{~mm}$ in $C, 0.5 \mathrm{~mm}$ in D and $E$. 
Head (Fig. 4A) bent to ventral side, with a pair of protrusions around anterior margin in front of eyes, bearing distinct setae; frons with paired setae between eyes near antennal insertions. Eyes moderately large, with distinct facets. Antenna with scape slender and transverse, antennomeres 2-11 longer than wide, extending posteriorly along the lateral margin of abdomen, reaching to the ventral side of fourth abdominal ventrite; each segment with several distinct spine-shaped protrusions around the apex and several short setae near middle.

Prothorax (Fig. 4B) sub-quadrate with paired apical protrusions that are expanded apically, bearing a long seta on each side. Anterolateral area with pair of protrusions that are distinctly bifurcate apically, bearing two setae on each side. Lateral margins with two pairs of small and triangular protrusions anteriorly and two posteriorly, each protrusion bearing a long seta. Posterior area with pair of setae on dorsal side. Mesothorax transverse with long wing pads on dorsal side, sterna with moderately broad sternal process. Metathorax relatively large, also with long wing pads, sterna with distinct discrimen. Elytron on ventral side, covering parts of pterothorax, abdominal ventrites and hind legs; surface with weak grooves. Legs relatively long, with compact femora and tibiae transversely located, tarsi longitudinal; fore and mid femora with three distinct lateral setae while hind femora only have one on each side.

Abdomen with eight exposed tergites, tergite I-VII from transverse to sub-triangular, the last two segments concealed by skin of last instar larva; segments II-IV with short lateral protrusions bearing distinct setae, segments V-VII with longer transversely lateral setigerous protrusions, tergite $\mathrm{VI}$ also with pair of posterolateral setae. Ventral side with five exposed ventrites, ventrite 5 from
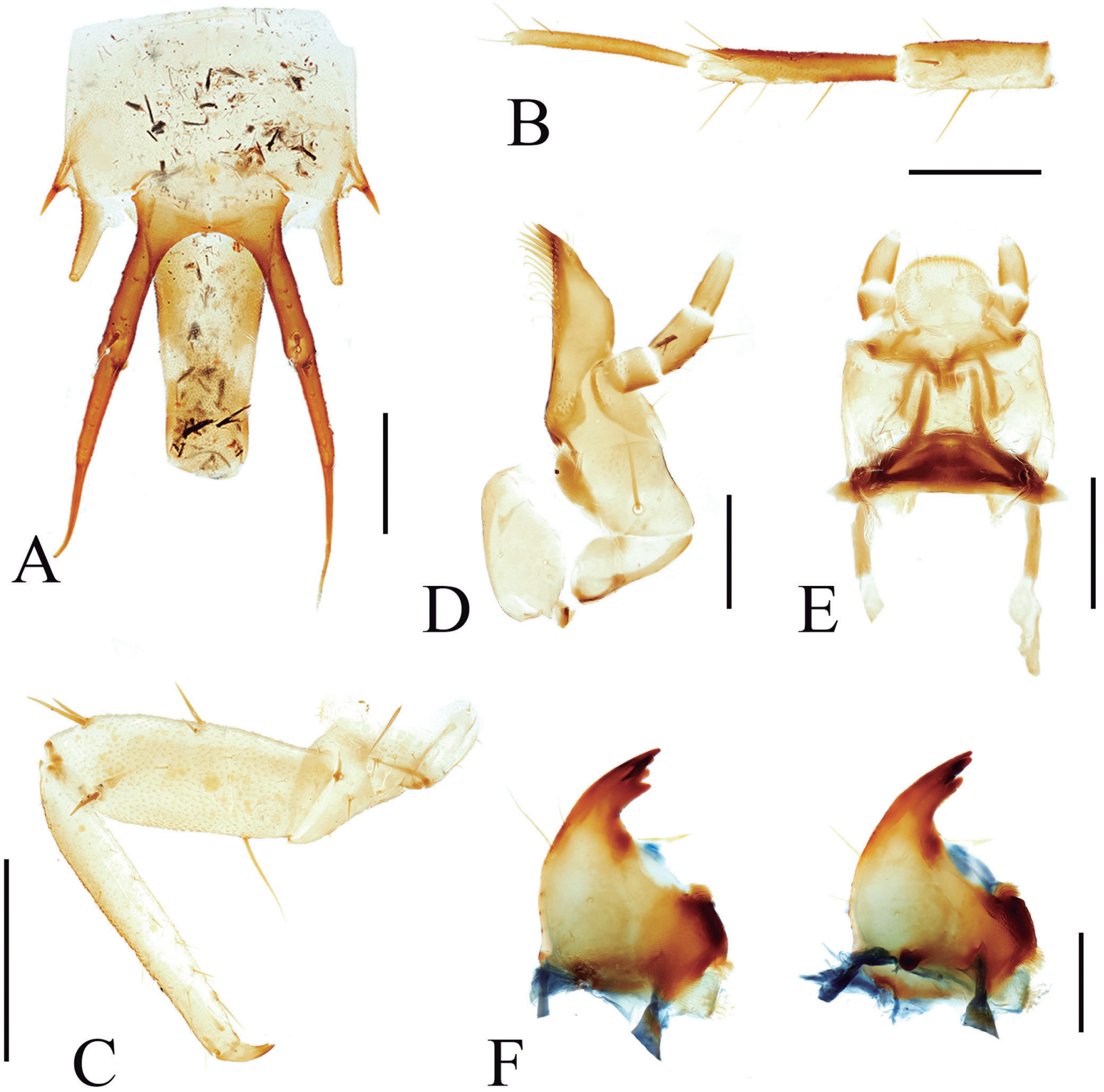

Figure 2. Larva of Macrohyliota militaris (Erichson). (A) Abdomen, terminal segments, dorsal view, (B) right antenna, (C) left leg, (D) right maxilla, ventral (E) labium, ventral (F) left mandible in dorsal view, right mandible in ventral view. Scale bars: $0.5 \mathrm{~m}$ in A-C, $0.2 \mathrm{~mm}$ in D-F. 
transverse to sub-triangular as matured; the first two sternites absent, the last three sternites and urogomphi are concealed by the exuvium of last instar larva.

Biology: Larvae and adults specimens were collected under bark of a dead Eucalyptus tree (Figs. 5A, 5C), moving quickly after being exposed. Larvae were observed in the lab grazing on spores and decaying bark. Dark tissues and spores were clearly visible in the esophagus and gut (Fig. 5A), confirming that the larvae feed on the rotten tissues of dead Eucalyptus and the fungi growing on it. Pupae were attached to the wood or bark substrate at the apex of abdomen (Fig. 5B).

Specimens examined: Australia, ACT: $35.27^{\circ} \mathrm{S} 149.11^{\circ} \mathrm{E}$ Canberra, Black Mt. 20/05/2017 Under bark of Eucalyptus, Zhenhua Liu (2 larvae dissected; 1 larva mounted on card; 1 larva, 2 adults and 1 pupa preserved in ethanol; ANIC).

\section{DISCUSSION}

Larval characters are most often used to support higher level classifications of beetles (Lawrence et al., 2011;
Leschen et al., 2005), however the morphological characters of larvae at the genus or species level are often not easy to find and describe. All known larvae of Brontini are very uniform and distinctive, sharing the following characters: body lightly sclerotized, dorsally flattened and parallel-sided body (Figs. 1A-B); the thoracic and abdominal terga lack sclerotized plates or large groups of asperities; head large, transverse, with 5 stemmata on each side; antennae long and slender; urogomphi elongate, articulated and bifurcate (Fig. 2A) and pygopod terminal, tube like. The larva of the Australian species described here is externally very similar to the Asian Macrohyliota sculptus Yoshida \& Hirowatari (Yoshida \& Hirowatari, 2016), but differs from it in the much larger body size (10-11 $\mathrm{mm}$ as compared to 1.8-2.1 $\mathrm{mm}$ ), having distinct frontal arms and the front femur with one more medium length seta on the outer margin near middle. The larva of Macrohyliota resemble those of the other Brontini genera, like Dendrophagus, Megahyliota, Uleiota and Australohyliota (Cekalovic \& Quezada, 1972; Yoshida \& Hirowatari, 2016), with apparent differences present in the ratios of the antennomere length and the shape of the maxilla. In Macrohyliota, the antennal pedicel is slightly longer than flagellum and each is less than 1.4 times as long as scape. In contrast, each of these antennomeres is more than 1.6 times longer than scape in Dendrophagus,
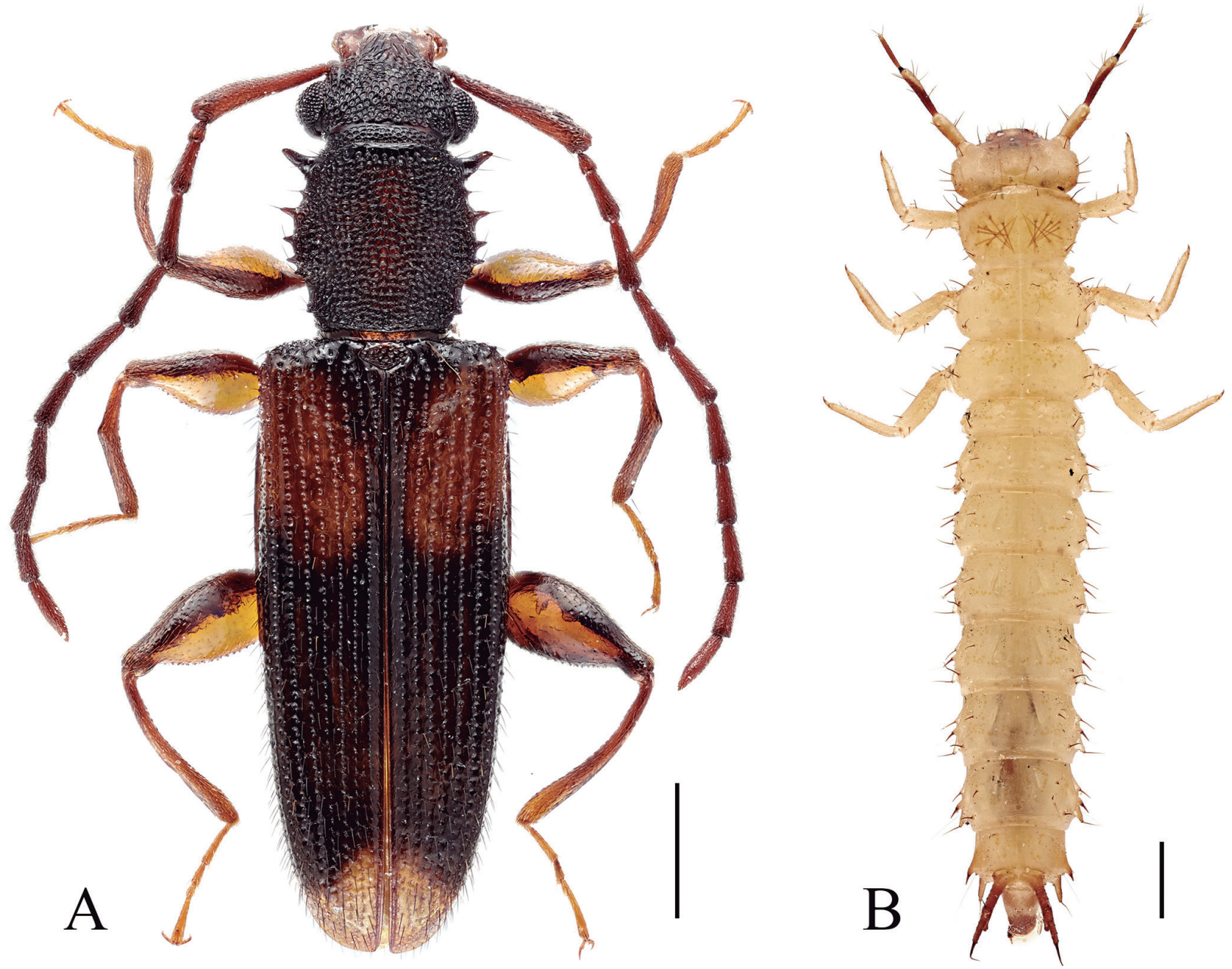

Figure 3. Habitus of Macrohyliota militaris (Erichson). (A) Adult, dorsal, (B) prepupa, dorsal. Scale bars: $1 \mathrm{~mm}$. 
Megahyliota and Uleiota. In addition, the pedicel in Uleiota is more than 2 times as long as the scape. The larva of the Chilean Austrahyliota chilensis (Blanchard) has similar ratios between pedicel and flagellum as in Macrohyliota, but the flagellum is shorter than the scape. Furthermore, the mandibular penicillus appears to offer a potential key character for distinguishing genera of larval Brontini. The two species of Macrohyliota have two basal penicilli, Dendrophalus longicornis Reiter has a small basal penicillus, Megahyliota cryptolucidus Yoshida \& Hirowatari has a large and transverse basal penicillus and Uleiota arboreus

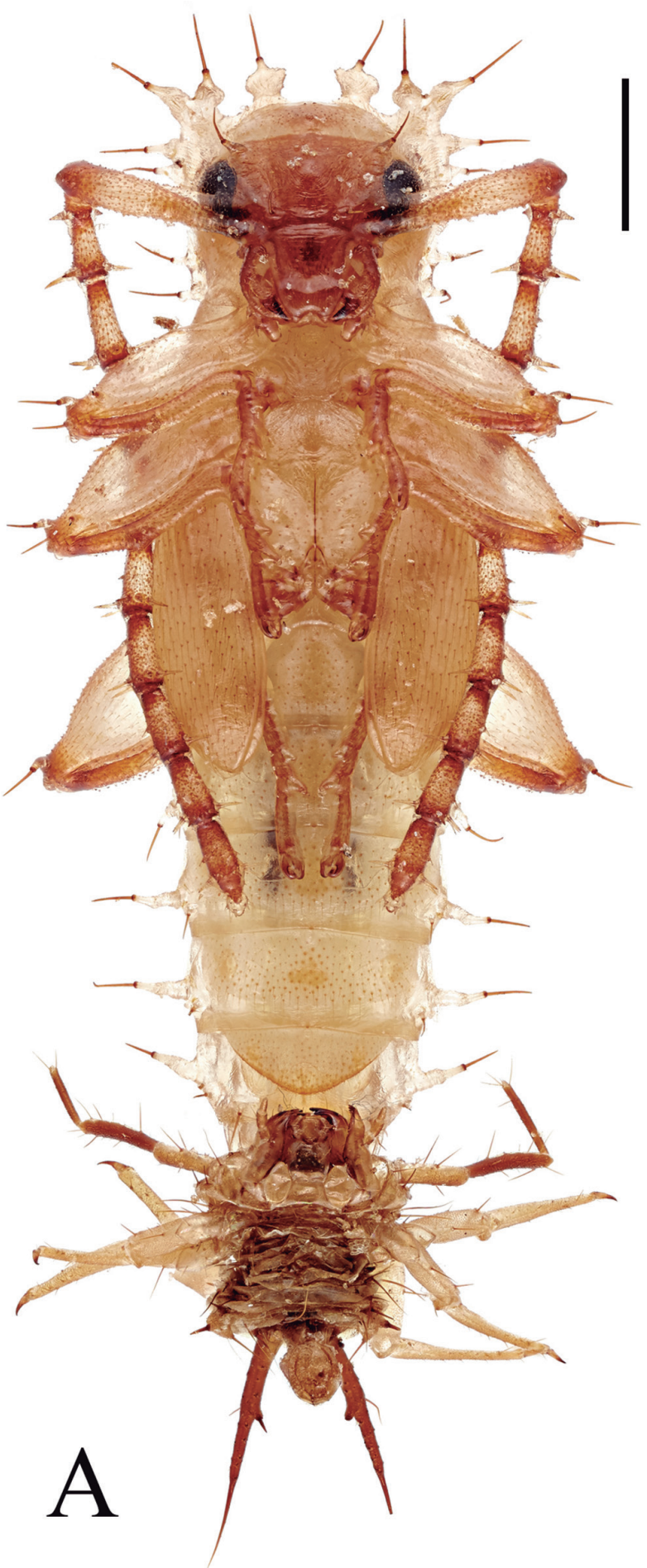

(Reitter) has a medium sized basal penicillus (Yoshida \& Hirowatari, 2016). The pupa of $M$. militaris shows notable differences from $M$. sculptus. In addition to its larger size, the paired anterior protrusions in $M$. militaris are distinctly larger and more expanded apically than in M. sculptus, and it has much fewer spine-shaped protrusions on antennae compared to M. sculptus. The described pupae of other genera in Brontini differ from Macrohyliota by the position of antennae and wings, which are strongly separated from the body in Megahyliota and Uleiota. Also, the protrusions on the antennae and the pronotum which

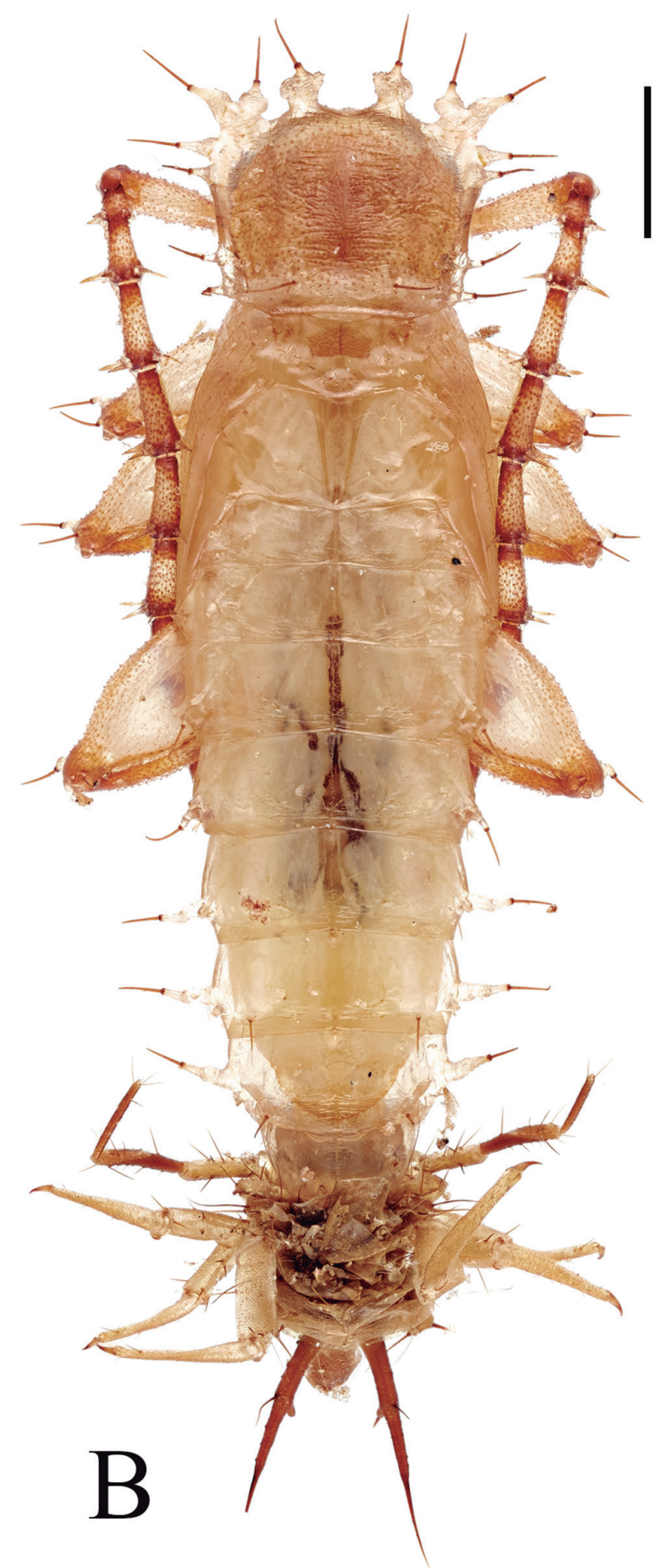

Figure 4. Habitus of Macrohyliota militaris (Erichson), pupa. (A) Ventral view, (B) dorsal view. Scale bars: $1 \mathrm{~mm}$. 


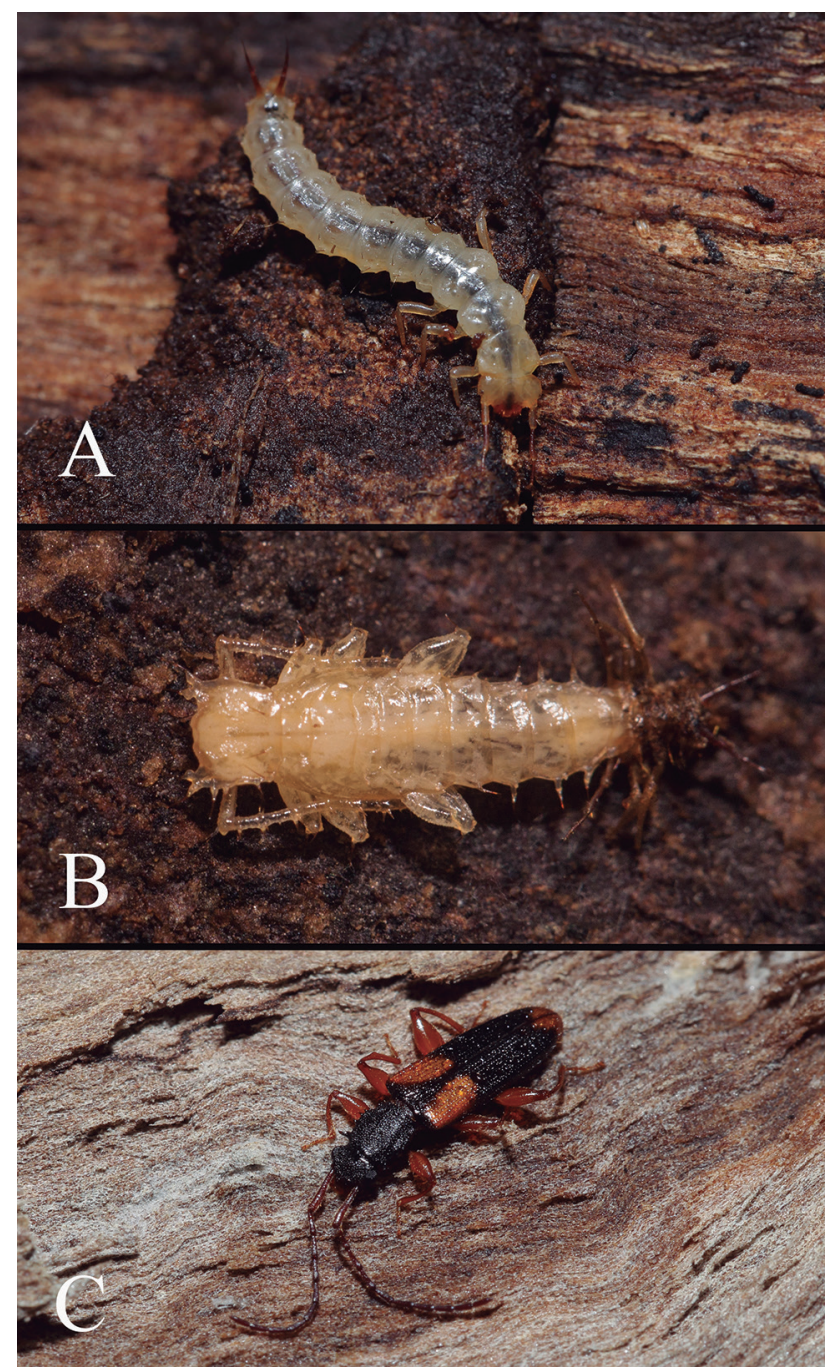

Figure 5. Habitats of Macrohyliota militaris (Erichson). (A) larva, (B) pupa, (C) adult.

are only weakly developed in Megahyliota and Uleiota (Yoshida \& Hirowatari 2016).

\section{ACKNOWLEDGEMENTS}

We are grateful to John Maris and another anonymous reviewer for their helpful suggestions to improve the manuscript. This study was funded by the following grants: Key project of Science-technology basic condition platform from The Ministry of Science and Technology of the People's Republic of China (No. 2005DKA21402); the specimen platform of China, teaching specimens sub-platform, Web, http://mnh.scu.edu.cn; and AS, Open project of the State Key Laboratory of Biocontrol (Grant No. 2018-04).

\section{REFERENCES}

Cekalovic, K.T. \& Quezada, A.E. 1972. Distribución geográfica de Uleiota chilensis (Blanchard), 1851 y descripción de la larva (Coleoptera: (ucujidae). Boletin de la Sociedad de Biología de Concepción, 44: 17-22.

Hayashi, N. 1980. Illustrations for identification of larvae of the Cucujoidea (Coleoptera) found living in dead trees in Japan. Memoirs of the Education Institute for Private Schools in Japan, 72: 95-147.

Hudson, G.V. 1934. New Zealand beetles and their larvae: an elementary introduction to the study of our native Coleoptera. Wellington, NZ, Ferguson \& Osborne.

Karner, M.; Salvato, G. \& Uliana, M. 2015. A new genus and new species of Telephanini (Coleoptera: Silvanidae) from Gabon. European Journal of Taxonomy, 130: 1-10.

Klausnitzer, B. 2001. 75. Familie Silvanidae. In: Klausnitzer, B. (Ed.). Die Larven der Kafer Mitteleuropas. 6 Band. Polyphaga. Teil 5. Heidelberg, Spektrum Academischer Verlag. p. 138-150.

Lawrence, J.F.; Ślipiński, A.; Seago A.E.; Thayer M.K.; Newton A.F. \& Marvaldi, A.E. 2011 Phylogeny of the Coleoptera based on morphological characters of adults and larvae. Annales Zoologici, 60(1): 1-217.

Leschen, R.A.; Lawrence, J.F. \& Ślipiński, S.A. 2005. Classification of basal Cucujoidea (Coleoptera: Polyphaga): cladistic analysis, keys and review of new families. Invertebrate Systematic, 19(1): 17-73.

Marris, J.W.; Hawke, D. \& Glenny, D. 2019. Eating at high elevation: An herbivorous beetle from alpine rock outcrops relies on ammoniaabsorbing lichens. Ecology, 100(5): e02598. DOI

Pal, T.K. \& Baraik, B. 2012. On a collection of Silvanidae (Coleoptera: Cucujoidea) from Arunachal Pradesh, India with two new species and a larva. Records of the Zoological Survey of India, 112: 61-84.

Pal, T.K.; Sen Gupta, T. \& Crowson, R.A. 1984. Revision of Uleiota (Coleoptera: Silvanidae) from India and Sri Lanka and its systematic position. Oriental Insects, 18: 213-233.

Thomas, M.C. 1984. A new species of apterous Telephanus (Coleoptera: Silvanidae) with a discussion of phylogenetic relationships of the Silvanidae. The Coleopterists' Bulletin, 38(1): 43-55.

Thomas, M.C. 1988. Generic key to the known larvae of the Cucujidae, Passandridae, and Silvanidae of America north of Mexico (Coleoptera). Insecta Mundi, 2(2): 81-89.

Thomas, M.C. 2003. The Brontini of the world: A generic review of the tribe (Coleoptera: Silvanidae: Brontinae). Insecta Mundi, 17(1-2): 1-31.

Thomas, M.C. 2011. A new genus and species of brontine Silvanidae from Australia (Coleoptera: Cucujoidea). Insecta Mundi, 0154: 1-8.

Thomas, M.C. \& Leschen, R.A.B. 2010. Silvanidae. In: Leschen, R.A.B.; Beutel, R.G. \& Lawrence, J.F. (Eds.). Handbook of zoology, coleoptera, beetles, vol. 2: morphology and systematics (Elateroidea, Bostrichiformia, Cucujiformia partim). Berlin, Walter de Gruyter. p. 346-350.

White, F.B. 1872. Contributions towards a knowledge of the life-histories of certain Coleoptera. I. Dendrophagus crenatus, Payk. Entomologist's Monthly Magazine, 8: 196-198.

Yoshida, T. \& Hirowatari, T. 2016. Taxonomic revision of the tribe Brontini (Coleoptera: Silvanidae) in Japan and Taiwan with reference to their larval and pupal morphologies. Annals of the Entomological Society of America, 109(2): 252-279.

Yoshida, T. \& Hirowatari, T. 2018. A new genus and species of Brontinae from Borneo (Coleopera, Silvanidae). Zookeys, 805: 45-57.

Yoshida, T. Hirowatari, T. \& Hashim, R. 2017. A new genus of Silvaninae (Coleoptera: Silvanidae) with two new species from the Malay Peninsula. Zootaxa, 4258(4): 365-374. 